doi:10.12662/2359-618xregea.v10i1.p89-105.2021

\title{
MARKETING ESPORTIVO E FIDELIDADE: O RELACIONAMENTO DE SÓCIOS-TORCEDORES COM O CENTRAL SPORT CLUB
}

\author{
SPORTS MARKETING AND LOYALTY: \\ SUPPORTERS' RELATIONSHIP WITH CENTRAL \\ SPORT CLUB
}

\section{RESUMO}

Este artigo visa discutir as estratégias de marketing esportivo usadas na gestão do relacionamento com o sócio-torcedor do Central Sport Club, time de Caruaru, no interior de Pernambuco. Considerando o caso do Central Sport Club, foi realizada entrevista com Diretoria de Marketing, e foram aplicados questionários junto a 114 sócios para analisar o nível de relacionamento de cada torcedor com esportes em geral, como eles se definem como torcedor, a representatividade do time Central na vida de cada um e quais os níveis de satisfação com as políticas adotadas pelo clube. Observou-se que o clube se destaca na quantidade de torcedores associados e na satisfação destes com o preço de ingressos e planos de sócios/ categorias. Faz-se necessário, ainda, implementar estratégias para manter a quantidade de sócios adimplentes com o clube, bem como fidelizar novos torcedores, buscando superar dificuldades gerais enfrentadas por clubes brasileiros, mas, em especial, entre times no interior do Estado.

Sara Verissimo Silva sara_carolyne@hotmail.com Bacharel em Administração com ênfase em Marketing de Moda pela Universidade de Pernambuco. Recife-PE-BR.

Adriana Tenório Cordeiro adriana.cordeiro@upe.br Doutora em Administração pelo PROPAD/UFPE. Professora Adjunta da Universidade de Pernambuco. Recife-PE-BR.

Paula Gonçalves da Silva paula.goncalves@upe.br Doutora em Administração pelo PROPAD/UFPE. Professora Adjunta da Universidade de Pernambuco. Recife-PE-BR.
Palavras-chave: Marketing Esportivo. Marketing de Relacionamento. Sócio-torcedor. Fidelidade. Futebol.

\begin{abstract}
This article aims to discuss the sports marketing strategies used in the relationship management with the Central Sport Club's partner-fan, a team from Caruaru, in the countryside of Pernambuco. Considering the case of Central Sport Club, an interview was conducted with the Marketing Director, and questionnaires were applied to 114 members to analyze the level of relationship of each fan with sports in general, how they define themselves as fans, the representativeness of the Central team in each one's life and what are the levels of satisfaction with the policies adopted by the club. It was observed that the club stands out in the quantity of associat-
\end{abstract}


ed fans and in their satisfaction with ticket prices and membership plans / categories. It is still necessary to implement strategies to maintain the number of members in good standing with the club as well as to build loyalty among new fans, seeking to overcome general difficulties faced by Brazilian clubs, but especially among teams within the state.

Keywords: Sports Marketing. Relationship Marketing. Supporter. Loyalty. Soccer.

\section{INTRODUÇÃO}

A Economia dos Esportes no Brasil movimenta bilhões de Reais e gera milhares de empregos, sendo o futebol o esporte mais conhecido do mundo e aquele que movimenta mais capital financeiro em seus projetos e negociações. Apenas a Confederação Brasileira de Futebol - CBF teve receita de R\$ 957 milhões em 2019, um aumento de 43,3\% em relação a 2018, e com investimentos no futebol superando R \$ 535 milhões no mesmo ano. Essa arrecadação se deve, em especial, a patrocínios, direitos de transmissão e comerciais e legados da Copa do Mundo de 2014 (CBF, 2020). Os clubes brasileiros, por sua vez, faturavam quase R \$ 6 bilhões por ano, uma vez que, no ranking dinâmico das receitas dos clubes brasileiros, já se observava a liderança do Flamengo, do Palmeiras e do Corinthians, sobretudo devido a patrocínios, a bilheterias (SPORTS VALUE, 2020), além da venda de imagem, contratos profissionais e venda de atletas, o que também repercute, fortemente, nas receitas dos clubes (SILVA, 2010).

A gestão dos clubes de futebol, por sua vez, passa por constantes transformações. Havia épocas em que os clubes viviam, exclusivamente, de vendas de ingressos e patrocínios, mas hoje a busca ultrapassa essas duas fontes para incluir o aumento na quantidade de sócios-torcedores, a venda de produtos relacionados à marca e o Marketing. O Marketing Esportivo, para Bechara (2001), visa desenvolver o esporte por meio da aplicação de conhecimentos da administração e do marketing nas três manifestações esportivas - formação, participação e performance, para a satisfação dos usuários. Fatores que relacionam futebol e marketing merecem atenção, principalmente quanto à esfera do planejamento em clubes de médio e pequeno porte, os quais, geralmente, sofrem mais por não jogarem o calendário anual completo.

A relação marketing-esporte segue duas direções: as ações de marketing ligadas ao produto esporte, o chamado de marketing esportivo, e as relacionadas a outros produtos, esportivos ou não. A primeira se refere a todo o planejamento de marketing relacionado ao produto esporte (competição, equipe esportiva ou modalidade como o futebol, por exemplo) e a segunda a ações de marketing no esporte, as quais utilizam a imagem do esporte como apelo, seja na publicidade, seja no patrocínio (YANAZE, 2011). Nesse cenário, os patrocínios são cruciais a um clube de futebol, principalmente quando possuem patrocinadores master (principal patrocinador dos clubes), a exemplo do patrocínio master do Palmeiras (a Crefisa). As empresas se associam às marcas em busca de ganhos de imagem, exposição e vendas.

O marketing esportivo traz junto com o marketing de relacionamento diversas estratégias para os clubes. Este pode ser entendido como o uso de recursos do marketing para entender o comportamento do consumidor, utilizando dados eficientes, gerados por pesquisas para gerenciamento dos relacionamentos com os clientes, bem como programas de fidelidade (COSTA; MOTA, 2016).

Gestores de clubes perceberam que possuem os clientes mais fiéis da esfera de negócios, e a estratégia consiste em saber como estimular os torcedores a compartilharem mais benefícios com os clubes, ao invés de limitar sua atuação apenas à compra de ingressos e às idas aos jogos. A ideia se refere a proporcionar um sentimento maior de participação conjunta com o clube, tanto social como financeiramente; daí surgiu o programa sócio-torcedor, para fidelizar o torcedor, trazendo sentimento de participação, além de oferecer benefícios, gerar receita para o clube 
e deixar o sócio mais fiel à marca. Borges (2020) apontava que, no início de 2020, os times que tinham a maior taxa de sócios inadimplentes eram São Paulo, Corinthians e Ceará. No caso do São Paulo, apesar de se destacar nos programas de sócio-torcedor, a dificuldade seria de manter o interesse da torcida.

Considerando a gestão no futebol e sua importância econômica e cultural para o país, o presente artigo tem como objetivo principal identificar as estratégias de marketing esportivo usadas na gestão do relacionamento com o sócio-torcedor do Central Sport Club, time de Caruaru-PE, a partir da análise da percepção de seus clientes mais ativos (os torcedores). O Central Sport Club joga, atualmente, na primeira divisão do campeonato pernambucano. Fundado em 15 de junho de 1919, o clube centenário possuía uma cartela aproximada de 700 sócios em 2019. Essa pesquisa é motivada pela importância de se estudar os clubes do interior e pelas lacunas de conteúdo ligadas ao tema no que concerne ao relacionamento com sócios-torcedores. Os clubes do interior acabam sendo os mais afetados por não contarem com grandes patrocínios e não obterem a mesma cartela de sócios dos times maiores. Tais aspectos reforçam a importância do estudo à medida que pode contribuir para informar a concepção de estratégias exitosas para esses clubes, considerando perspectivas de médio e longo prazos.

\section{REFERENCIAL TEÓRICO}

\subsection{MARKETING ESPORTIVO E O FUTEBOL}

A base dos estudos em marketing esportivo é formada por campos diversos que incluem o estudo dos esportes, o estudo da administração de empresas, as ciências sociais e a comunicação. Pitts e Stollar (2002) enfatizam que o processo de elaborar e implementar as atividades de produção, como a formação de preço, promoção e distribuição para satisfazer a necessidade ou os desejos dos consumidores também são aspectos do marketing esportivo.
Os autores observam o marketing esportivo, uma função da administração no esporte, como negócio, que tem como principais objetivos aumentar o reconhecimento público, criar e garantir elo com o consumidor, garantir exposições de produtos e garantir a credibilidade da marca. De forma basilar, os estudos de marketing esportivo se voltam para as relações de troca entre os produtores que oferecem os produtos esportivos e os consumidores, sejam torcedores, sejam praticantes (SANTOS; PAROLINI, 2020).

A definição técnica do conceito marketing esportivo para o século XXI é de uma modalidade de marketing estratégico de caráter experimental, vivencial e emocional que desperta vontade do consumo do esporte e suas distintas formas e conteúdo, utilizando o principal elemento ativador do seu mix: a Paixão (MELO NETO, 2013). Neste sentido, na esfera do marketing esportivo, estão compreendidas ações e estratégias que visam à implementação de atividades e melhoria de imagem das marcas ligadas ao esporte. No marketing esportivo, estão presentes os 4P's: produto, preço, praça e promoção. O futebol consegue mexer com o sentimento de milhares de pessoas e não fica restrito apenas aos 90 minutos de um jogo em campo, a paixão dos brasileiros pelo futebol é compreendida pelo termo 'Paixão além dos 90 minutos', o que é muito válido para os clubes, pois envolve os torcedores ainda mais com seus eventos e produtos. Para Silva (2010, p. 25), "no Brasil, o futebol é uma paixão que se confunde com a forma de ser do nosso povo. Por aqui, podemos afirmar, sem medo de errar, que o futebol é a nossa maior expressão cultural.” O futebol impacta economia, cultura e desenvolvimento social.

O quinto 'P' da 'Paixão' pode ser observado quando o emocional atinge o seu limite máximo no momento de um jogo ou de uma competição, quando a paixão de torcer é o desejo de vencer, e a maior decepção é perder, e são aqueles momentos presenciados que se tornam memoráveis, para lembrar, contar, e comemorar novamente. O domínio do 'P' de paixão 
sobre os demais elementos do mix de marketing tradicional é o que traz ao marketing esportivo um diferencial significativo, à medida que é uma modalidade que move paixão e visa à emoção antes, durante e depois de realizado o consumo do produto esportivo (MELO NETO, 2013). Essa ênfase extrapola os limites físicos das instalações esportivas, alcançando tanto os espectadores que acompanham a disputa no campo, quanto os que acompanham as transmissões por meio das diversas mídias (MARTINS, 2018). Melo Neto (2013) destaca ainda que, atualmente, o futebol ganha muita relevância, seu mercado de fãs e praticantes vêm aumentando, consideravelmente, sua audiência em rádios e televisão, atingindo índices bastante elevados. Assim, torna-se alvo de investimento público e, principalmente, privado, assumindo papel de agente de desenvolvimento da indústria do esporte e do entretenimento esportivo.

Com a força que o futebol possui nas mídias e o elevado índice de audiência, emerge o patrocínio esportivo em busca de ganhos de imagem, exposição e vendas. As empresas patrocinadoras firmam parcerias com marcas de entidades esportivas. O patrocínio esportivo é, assim, um instrumento de negociação que envolve as empresas e as entidades esportivas, juntos, formando uma parceria e uma relação benéfica para ambas as partes (MELO NETO, 2013). Não se trata apenas de se obter a marca estampada nos uniformes dos jogadores. $\mathrm{O}$ patrocínio se tornou mais do que isso dentro dos clubes e está ligado à manutenção do relacionamento entre patrocinador, clube e torcedor. Quando uma empresa procura um clube para patrociná-lo, busca potencializar a exposição de sua marca, agregar valor à imagem e alavancar os benefícios dos parceiros, podendo gerar novas oportunidades de negócio (DUALIB, 2005; RAFIH, 2015).

A relação entre empresa patrocinadora e clube patrocinado é um exemplo de parceria benéfica, dado que os clubes necessitam dos patrocinadores para seu fluxo de caixa. E as empresas aumentam a visibilidade de suas marcas, relacionando-se com os clubes, por isso os maiores e milionários patrocínios estão nos grandes clubes das capitais, as vitrines que os grandes clubes possuem chamam a atenção das empresas patrocinadoras, gerando interesse de diversas marcas (MELO NETO, 2013). A seguir, abordaremos:

\subsection{MARKETING DE RELACIONAMENTO, COMUNICAÇÃO E FUTEBOL}

Várias são as percepções acerca do marketing de relacionamento, enfatizado pela importância de se obter uma maior relação entre as próprias empresas e mais importante ainda a relação empresa-cliente. O marketing de relacionamento é o processo que envolve criar, manter e fomentar relações de longo prazo entre organizações e pessoas, priorizando valores e importância de cada relação. A fidelidade de um consumidor a uma empresa está diretamente ligada ao nível de satisfação estabelecida entre ambas as partes (PACHECO, 2001).

No mundo do futebol, não é diferente. Porém, o futebol é um dos poucos serviços embora os clientes não estejam satisfeitos, não deixam de torcer e voltam a consumir novamente o serviço e se fazem presentes em longas filas para a compra de ingressos, por exemplo, mesmo estando na chuva ou no sol.

O futebol se divide em três mercados: o produtor, o consumidor e o intermediário. $\mathrm{O}$ produtor oferece o serviço. Encaixam-se, nessa categoria, os clubes de futebol, a federação e seus dirigentes. No intermediário, ficam as áreas de revenda, empresas licenciadas e a televisão por exemplo. O mercado consumidor é um dos mais importantes; com ele estão os torcedores, os clientes fiéis às marcas dos clubes (AVANCINI, 2010).

Neste sentido, a necessidade de conquistar novos clientes, e não apenas isso, manter clientes leais, impulsiona o relacionamento das empresas com seus clientes, ampliando a ideia do marketing de relacionamento. Esse conceito envolve o desenvolvimento dos relacionamentos entre uma companhia e clientes, oferecendo 
benefícios e enfatizando a qualidade no serviço/ produto, para conseguir atingir o grau máximo de satisfação dos clientes e assim gerar lealdade em longo prazo (CROCCO et al., 2009).

O futebol no mundo inteiro proporciona a seus torcedores emoção, prazer e orgulho de fazer parte de um determinado clube. O torcedor de um time, em sua maior parte, tem, em seu clube do coração, uma forma de 'ideologia', permanente. Ele pode mudar de cidade, de profissão, mudar seus gostos, mas não muda de time, independentemente do desempenho de seu clube (AIDAR; FAULLIN, 2013). Assim, a maneira como o futebol mexe com o sentimento dos torcedores, e atua, principalmente, na emoção, muitas vezes até parecendo 'escapar' da dimensão da razão, acaba tornando mais propícia a atuação do marketing de relacionamento nessa esfera. A tarefa do novo modelo de gestão dos clubes envolve contemplar o torcedor, não apenas como torcedor, mas, sim, como cliente mais ativo do clube. Assim como toda e qualquer empresa tem seu público-alvo, os clubes de futebol têm seus torcedores como público-alvo. O departamento social de um clube deve definir em qual faixa de renda eles se enquadram e montar estratégias que possam alocar cada um à sua esfera (MOREIRA; LOBATO, 2014).

Com a dinâmica do mercado, as organizações precisam estar atentas aos anseios, aos desejos e às necessidades dos seus clientes, buscando melhor compreendê-los. $\mathrm{O}$ foco no cliente sugere que não se pode focar apenas no produto ou no serviço, sendo cada vez mais necessário conhecer bem o público e, assim, desenvolver as estratégias necessárias para que se inicie um bom relacionamento (SILVA; ZAMBON, 2008). Nesta lógica, as redes sociais online passam a assumir vital importância para os clubes de futebol se aproximarem ainda mais dos torcedores. O Vasco, por exemplo, foi o clube que mais cresceu de 2019 para começo de 2020, em termos de ampliação de sócios-torcedores, com mais de 150 mil novas adesões ao plano 'Sócio Gigante', isso a partir de forte campanha nas redes sociais online (BORGES, 2020).
Existem diversas funcionalidades em uma rede social, mas a principal delas é a conexão estabelecida entre seus usuários. De acordo com Mokfianski e Alvetti (2017, p. 1):

\begin{abstract}
A internet é uma ferramenta útil para os clubes e as organizações esportivas ganharem popularidade por meio das redes sociais, causando uma revolução no modo como os torcedores e fãs se aproximam do esporte. Por isso, é importante que entendamos o perfil desses torcedores conectados, buscando tornar as redes sociais um meio de aproximação e relacionamento com esse novo tipo de público para que a marca do clube se fortaleça.
\end{abstract}

Avanços na área da comunicação digital trazem, pois, diversas mudanças para o segmento do futebol, mesmo que jornais, televisão e rádio ainda sejam os principais meios de comunicação utilizados para transmissão de jogos, anúncio de venda dos atletas e notícias dos clubes. Os contratos de direito de imagem dos clubes com as emissoras de televisão são, muitas vezes, milionários, e campeonatos como a Copa do Brasil, por exemplo, geram altos lucros para os clubes. Além disso, a televisão usa o esporte como meio para maximizar suas receitas, pois eventos atraentes como os grandes clássicos atraem anunciantes dispostos a exibir suas marcas (NOVELI; COSTA, 2018). No tópico a seguir, discutiremos aspectos ligados ao relacionamento entre sócio-torcedor e o clube enquanto marca.

\subsection{RELACIONAMENTO ENTRE SÓCIO-TORCEDOR E A MARCA DO CLUBE}

É possível destacar que boa parte da relação entre o torcedor e a marca do seu clube, geralmente, vem de gerações anteriores, como um amor herdado. O tamanho da torcida tende a ser o principal fator na determinação do potencial de receita de cada 
clube, os bens materiais e os jogadores são comprados ao longo do tempo, mas a torcida é diferente, ela está relacionada à tradição, ou seja, ao relacionamento histórico do torcedor com o Clube. O torcedor precisa ser visto de duas maneiras pela gestão dos clubes: como o cliente mais ativo que compra o serviço e como peça fundamental para a existência do espetáculo associado ao futebol (AIDAR; FAULLIN, 2013).

Não é comum ver torcedores trocarem de time por motivos de não conquista de títulos ou retorno a divisões inferiores. Esse fato é muito importante para o marketing, pois relaciona a fidelidade a uma marca. É difícil observar a fidelidade a um produto ou serviço em outras indústrias na mesma proporção que se observa no futebol. Não se trata apenas da satisfação com o 'produto', mas de uma relação emocional, na maioria das vezes, até mesmo uma relação de sofrimento, que pode ser contemplada também como uma relação comercial, se forem utilizadas estratégias adequadas quanto à relação torcedor-clube (AIDAR; FAULLIN, 2013).

O programa sócio-torcedor, que consiste em fidelizar o torcedor, trazendo sentimento de participação, além de oferecer benefícios, visa gerar receita para o clube e deixar o sócio mais fiel à marca. $\mathrm{O}$ programa ganhou muita força nos últimos anos e trouxe com ele resultados extremamente positivos, além de influenciar diretamente nas receitas dos clubes (AVANCINI, 2010). A criação do programa sócio-torcedor visa fortalecer o contato com os torcedores, trazendo, assim, a possibilidade de participação diária com o andamento do clube, por exemplo, adquirir ingressos de forma mais rápida, possuir acesso ao estádio de forma eficiente e participar das ações promovidas pelos clubes, contribuindo com a geração de receita extra para os cofres do time (MOREIRA; LOBATO, 2014). Em termos financeiros, os sócios-torcedores representam uma fonte de receita menos volátil, não apenas pelas mensalidades pagas aos clubes, mas também pela maior predisposição em comparecer aos jogos e em comprar itens com a marca licenciada dos seus times (MONTEIRO; DIAS; CARVALHO, 2019).

Considerando os conceitos do marketing esportivo e do marketing de relacionamento, os clubes estão investindo mais em planos de fidelização, formando uma participação conjunta em algumas decisões tomadas pelo clube já que, por exemplo, os sócios têm direito a votar em seus candidatos à Presidência do clube, e a cada eleição, um representante é escolhido por determinado grupo, e os sócios escolhem quem deverá assumir a gestão do clube. Grande parte dos clubes de futebol tem público de classes econômicas variadas. Nesses casos, são necessários programas de sócios diferentes para cada perfil, conseguindo-se, assim, alocar o maior número de torcedores possível e direcioná-los a planos de sócios-torcedores adequados.

A agilidade das informações associada à grande participação da imprensa permite aos torcedores conhecer mais de seus clubes do coração. Hoje a mídia consegue produzir debates que envolvem tanto os rendimentos dos atletas, como o próprio trabalho da gestão atual, trazendo também balanços financeiros, contratos atuais e diversas informações que deixam os torcedores mais informados (MELO NETO, 2013). Assim, com acesso às informações da mídia e participação direta no clube (via programa de sócio), o torcedor se torna mais ativo e conectado.

Existem diferenças entre torcedor-fã e torcedor-espectador, isto é, o torcedor 
fã tem um time, com o qual se identifica e torce pelo seu sucesso. Já o espectador está interessado no sucesso do jogo e gosta especificamente do esporte. Assim como empresas possuem clientes com diferentes perfis, os clubes também dispõem de torcedores distintos (SLOAN, 1989). Entre os diversos perfis, Rocco Junior et al. (2021, p. 75) destacam a importância das organizações que oferecem o esporte como um produto e conhecem 'quem' são os consumidores intensos no esporte, ou seja, "aqueles que manifestam forte e clara identificação, fidelização e comprometimento com suas práticas, bem como com seus ídolos, além de hábitos e costumes associados ao seu esporte preferido."

A Escala de Motivação dos Fãs do Esporte (Sport Fan Motivation Scale), proposta por Wann e Branscombe (1993), por sua vez, destaca os diferentes motivos que atraem as pessoas a consumirem determinadas marcas esportivas: o amor pelo futebol ou apenas uma fuga da realidade, um desejo de satisfação, uma sensação de pertencimento a determinada comunidade, a autoestima, os motivos e traços familiares, interesses econômicos, a busca por diversão, ou apenas o prazer estético. Considerando-se o perfil do consumidor, a responsabilidade por levantar informações demográficas, psicográficas, de opiniões e sugestões, informações sobre a percepção de marca, relacionamento, frequência de ida aos estádios e consumo de produtos é dos envolvidos na área de marketing dos clubes.

Com as informações necessárias e a criação de um banco de dados completo e atualizado, a entidade esportiva poderá trabalhar com maior probabilidade de obter sucesso ligado a seu planejamento, podendo, inclusive, distinguir seus torcedores fanáticos e ativos daqueles que são apenas espectadores (MELO NETO, 2013). A seguir, destacaremos os procedimentos metodológicos adotados neste estudo.

\section{METODOLOGIA}

Esta pesquisa segue a abordagem de estudo de caso (YIN, 2001), visto que a unidade de análise é o Central Sport Club. Essa estratégia metodológica é considerada pertinente para contemplar o objetivo do estudo, o qual consiste em identificar as estratégias de marketing esportivo usadas na gestão do relacionamento com o sócio-torcedor do Central Sport Club, time de Caruaru-PE, por meio da análise da percepção de seus clientes mais ativos (os torcedores). O Central Sport Club foi fundado em 15 junho de 1919, na cidade de CaruaruPE, e jogava, em 2019, na primeira divisão do Campeonato Pernambucano e quarta divisão do Campeonato Brasileiro. O clube é denominado como a $4^{\mathrm{a}}$ força de Pernambuco, sendo o clube mais tradicional do interior do estado. $\mathrm{O}$ Central, assim como outros times maiores, conta com departamentos Administrativo, Financeiro, Social, de Comunicação e de Marketing.

Inicialmente, foi efetuada uma pesquisa bibliográfica acerca do marketing esportivo e do marketing de relacionamento para subsidiar a etapa de análise; a pesquisa bibliográfica foi elaborada com o propósito de prover uma fundamentação teórica ao trabalho, bem como a identificação do estágio atual do conhecimento referente ao tema (GIL, 2017).

Foi realizada, em seguida, uma pesquisa de campo baseada em um levantamento (survey) junto a sócios-torcedores do clube para analisar a percepção do sócio-torcedor quanto ao relacionamento com a marca Central Sport Club bem como no tocante às ferramentas de marketing esportivo propostas pelo clube. O instrumento de coleta de dados para este levantamento junto aos sócios-torcedores consistiu em uma adaptação do arcabouço de Melo Neto (2013). De acordo com o autor, "as pesquisas de relacionamento têm como objetivo analisar o nível de envolvimento dos torcedores com o esporte que acompanha, bem como a relação às entidades esportivas as quais se associam." (MELO NETO, 2013, p. 166).

O formulário foi elaborado considerando 
três dimensões amplas, que são relação entre o sujeito e o esporte; a relação entre o sujeito e o Central Sport Clube, e o sujeito. Além da apresentação que destacava aos respondentes, o objetivo geral do estudo e o formulário foram compostos por perguntas fechadas, e uma pergunta aberta, totalizando 20 questões divididas em três partes, conforme descritas a seguir:

a) a primeira parte (07 questões) contempla o sócio-torcedor e a sua relação com o esporte: (1) Como você define a sua relação com o esporte? (2) Como você se define como torcedor? (3) Qual a importância do esporte para a sua vida? (4) Qual mídia você mais utiliza para acompanhar o esporte? (5) Quais produtos esportivos você mais consome? (6) Você vai aos locais dos jogos e competições esportivas? (7) Se sim, qual o fator mais determinante na sua decisão?;

b) a segunda parte (06 questões) avaliava sua relação com o Central Sport Club (1) Há quanto tempo você é sócio do Central Sport Club? (2) Como você melhor define a sua relação com o Central Sport Club? (3) Como você classificaria o seu relacionamento com o Central Sport Club? (4) Nível de satisfação com plano de sócio e suas categorias, preço dos ingressos e a área do estádio destinada aos sócios. A comunicação do clube com o sócio-torcedor; promoções, descontos e vantagens oferecidas pelo clube para sócios, segurança (5) Qual a principal ideia que você gostaria que fosse associada ao Central Sport Club ou à equipe e transmitida aos sócios $\mathrm{e}$ torcedores? (6) Pergunta aberta 'Em breves palavras, defina o que o Central Sport Club representa para você.;

c) na terceira parte, foram sete questões sobre perfil, incluindo gênero, idade, renda familiar mensal, estado civil, profissão, número de filhos e grau de instrução.
Os sujeitos de pesquisa foram os sócios-torcedores do clube Central, durante o mês de maio de 2019, momento em que o time disputava o Campeonato Brasileiro e pôde-se aproveitar o maior engajamento dos torcedores. O Universo da pesquisa compreende, assim, os sócios-torcedores do Central Sport Club em situação regular com o clube, um total de 259 indivíduos. A amostra por conveniência foi composta por 114 indivíduos, considerando a sua disponibilidade para responderem ao formulário.

O formulário foi aplicado por meio eletrônico (formulário online do Google Forms) com sócios-torcedores, tendo sido enviado via redes sociais online e grupos de WhatsApp a partir do consentimento da Diretoria do clube. $\mathrm{Na}$ fase de análise, foram realizadas análises estatísticas descritivas simples que incluíram médias e distribuição de frequência.

Para análise dos dados qualitativos obtidos da pergunta aberta do formulário, foi usada a Análise Temática (AT), para identificar, analisar e reportar padrões (temas) contidos nos dados, em especial, ligados a motivações, a experiências e sentidos associados ao tópico de pesquisa (BRAUN; CLARKE, 2006). A operacionalização da AT seguiu as fases: familiarização com os dados; busca de temas; revisão de temas; definição e nomeação de temas.

No âmbito do estudo de caso, devem ser contempladas questões para promover o melhor entendimento do fenômeno (LEÃO; PAIVA JÚNIOR; MELLO, 2016). Neste sentido, foi realizada entrevista em profundidade com a Diretoria de Marketing do clube para conhecer melhor a situação atual do clube, os dados estatísticos, planejamentos e as perspectivas quanto à política de parcerias do clube. A equipe do clube foi receptiva e atenta a todas as perguntas e detalhes, tendo consentido com a realização do estudo. A entrevista em profundidade, de acordo com Richardson (1999, p. 2018), em vez de responder à pergunta por meio de alternativas pré-formuladas, visa obter do entrevistado o que ele considera mais relevante acerca de um dado problema ou assunto. Foram consideradas as opiniões do entrevistado como con- 
teúdo complementar a nortear compreensão do caso em questão. A seguir, discutiremos o caso do Central à luz desses esforços de pesquisa.

\section{DISCUSSÃO}

\subsection{SÓCIOS-TORCEDORES DO CENTRAL SPORT CLUB E O PROGRAMA SEJA SÓCIO PATATIVA}

Dos 114 sócios participantes na pesquisa, o público masculino corresponde a $88,5 \%$, enquanto $11,5 \%$ são do público feminino. Em relação à faixa etária, essa variou entre 'menor de 18 anos' e 'acima de 76'. A maior parte dos sócios tem de 26 a 35 anos (36,8\%), visto que o público de 18 a 35 anos soma $67,7 \%$ dos respondentes. A menor parte dos respondentes estão entre 51 e 75 anos, totalizando $7,1 \%$. O público menor de 18 anos representa $1,8 \%$, enquanto o público de 36 a 50 anos representa $27,2 \%$.

É pertinente observar que, por meio de mudanças na gestão do Central Sport Club, foram traçadas diferentes estratégias, com repercussões importantes em termos de quantidade de sócios-torcedores. Entre as mudanças implementadas pelo clube, destaca-se, no Departamento Social, a ampliação de uma categoria de sócio para agora três categorias distintas, alcançando um maior quantitativo de perfis de torcedores associados (quadro 1).
De acordo com gestores do departamento social, o clube contava com, aproximadamente, 20 sócios inscritos em 2017 e, no ano de 2018, esse número subiu para 700 sócios inscritos, por meio das novas categorias apresentadas, um crescimento de aproximadamente $3500 \%$. O caso do Central converge com o que apontava Avancini (2010), em termos dos esforços mais recentes entre dirigentes de clubes, os quais estão trabalhando fortemente na captação de novos sócios para integrar cartelas de sócios-torcedores e clientes ativos (AVANCINI, 2010).

Existe, ainda, a relevante contribuição de gerações anteriores na escolha de um time das gerações seguintes. Grande parte das pessoas que se relacionam com um time teve, de alguma maneira, influência de gerações anteriores. O futebol é um amor que passa de geração a geração (AIDAR; FAULLIN, 2013), um aspecto suscitado no trecho a seguir, obtido a partir de questão aberta do formulário eletrônico:

Central é tudo! É amor de pai para filho, meu pai há 45 anos acompanha o Central, e eu assim serei! CENTRAL ATÉ MORRER! (T1 - Sócio-torcedor do Central Sport Club).

A bandeira alvinegra passada por gerações da minha família desde o meu avô centralino puro sangue e que hoje eu tenho o orgulho de levar esse amor e continuar a representa-lo por onde for passando assim para os mais novos que eu compartilhar do mesmo

Quadro 1 - Novas categorias de sócio-torcedor e benefícios ofertados

\begin{tabular}{|l|l|l|}
\hline \multicolumn{1}{|c|}{ Tipo } & Mensalidade & \multicolumn{1}{c|}{ Benefícios } \\
\hline $\begin{array}{l}\text { Sócio } \\
\text { Centenário }\end{array}$ & R $\$ 100,00$ & $\begin{array}{l}\text { Ingresso grátis em jogos em casa. } \\
\text { Direito à compra de mais (um) ingresso para a ala de sócios. } \\
\text { Direito a voto em eleição (apenas sócio em dia) } \\
\text { Desconto na loja oficial do clube. }\end{array}$ \\
\hline Sócio Patativa & $\begin{array}{l}\text { Mensalidade } \\
\text { R } \$ 40,00\end{array}$ & $\begin{array}{l}\text { Desconto em ingressos } \\
\text { Direito a voto em eleição (apenas sócio em dia) } \\
\text { Desconto na loja oficial do clube. }\end{array}$ \\
\hline $\begin{array}{l}\text { Sócio Campeão } \\
\mathbf{1 9 8 6}\end{array}$ & $\begin{array}{l}\text { Mensalidade } \\
\mathrm{R} \$ 20,00\end{array}$ & $\begin{array}{l}\text { Desconto em ingressos } \\
\text { Desconto na loja oficial do clube. }\end{array}$ \\
\hline
\end{tabular}

Fonte: dados da pesquisa de campo (2019). 
sentimento (T2 - Sócio-torcedor do Central Sport Club).

Nasci e me criei em berço centralino, amor sem medidas, e paixão por ser torcedora fanática!! (T3 - Sócio-torcedora do Central Sport Club).

Amor, paixão e emoção que tou passando para meus filhos e netos futuros (T4 - Sócio-torcedor do Central Sport Club).

No caso dos sócios-torcedores do Central entrevistados, a pesquisa identificou que $52,7 \%$ dos respondentes ainda não têm filhos, enquanto $19,6 \%$ têm apenas 1 filho, 19,6\% têm dois filhos, e $8 \%$ têm mais de dois filhos. Quanto à renda familiar mensal dos entrevistados, esta varia entre 'menos de $\mathrm{R} \$ 500,00$ ' até 'mais de $\mathrm{R} \$ 6.000,00$ '. A maior parte das famílias dos respondentes $(30,1 \%)$ possui renda que varia de $\mathrm{R} \$ 1.000,00$ a $\mathrm{R} \$ 2.000,00$. Enquanto $24,8 \%$ têm renda maior do que $\mathrm{R} \$ 6.000,00$, $23 \%$ dos respondentes têm renda que varia entre $\mathrm{R} \$ 2.000,00$ a $\mathrm{R} \$ 4.000,00$. A minoria, que totaliza $8,8 \%$, varia na faixa de 'até $\mathrm{R} \$ 500,00$ ' até ‘menos de $\mathrm{R} \$ 1.000,00$ ’ (gráfico 1). sobre o comportamento do sócio-torcedor.

\subsection{RELACIONAMENTO DO SÓCIO- TORCEDOR COM O ESPORTE}

Nesta seção, discutimos a relação do torcedor com o esporte. Buscou-se investigar a importância do esporte na vida de cada indivíduo para avaliar como eles se identificam enquanto torcedor. Avaliamos a frequência com que os respondentes vão ao estádio, qual o fator determinante e quais as mídias mais utilizadas para acompanhar as notícias. Ao serem indagados sobre o seu relacionamento com o esporte, $69 \%$ dos entrevistados se relacionam com o esporte como 'torcedor e praticante', $28,3 \%$ se relacionam como apenas 'torcedor', e $0,9 \%$ se identifica como 'praticante' de esportes. Entende-se que o torcedor também é um grande consumidor, tanto do serviço, como do produto. O torcedor que vai aos locais das competições esportivas e, em suas horas de lazer, também pratica esportes, tem maiores chances de consumir produtos e acessórios relacionados à marca. Assim, consome serviços e produtos da marca, o que contribui

Gráfico 1 - Renda familiar mensal dos sócios-torcedores

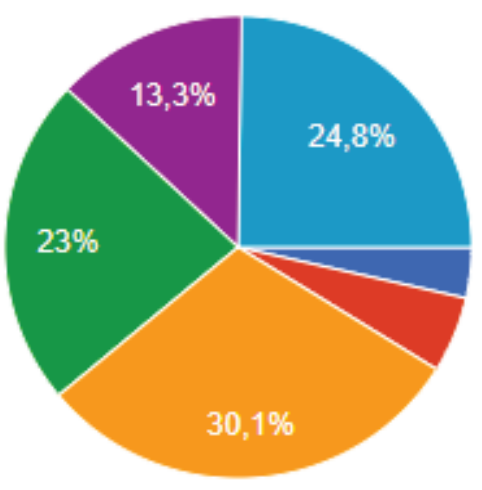

Fonte: dados da pesquisa de campo (2019).

É possível perceber que a renda mensal tem grande variação, informação que é de vital importância o clube conhecer para definir com mais precisão suas categorias e planos de sócios. O clube pode buscar, assim, atender à necessidade de cada um para não excluir nenhum torcedor. Além disso, compete ao clube acompanhar a dinâmica dessa renda e seus impactos diversos diretamente para receitas do clube em vendas de produtos e acessórios (MELO NETO, 2013).

Buscou-se, ainda, identificar como os respondentes se definem enquanto torcedor, uma vez que $56,3 \%$ se definem como sendo 'fanáticos', enquanto $32,1 \%$ são 'muito participativos', $10,7 \%$ são 'moderados', e apenas $0,9 \%$ se identificou como 'pouco participativo'. No 
tocante à importância do futebol na vida dos torcedores entrevistados, 51,3\% a classificaram como sendo 'muita', 38,9\% como 'total', 8,8\% como 'média' e $0,9 \%$ como 'pouca'.

De acordo com dados da pesquisa, coletados em 2019, todos os torcedores respondentes iam aos locais das competições esportivas. São diversos os fatores que contribuem para essas idas aos locais da competição, tais como 91,2\% respondentes comparecem 'para ver seu time jogar'; 3,5\% optam por comparecer em função da 'proximidade' do estádio em relação à sua residência; $2,7 \%$ têm como fator determinante o 'preço' (o item preço foi associado aos ingressos para entrada nos locais da competição); $1,8 \%$ vai em função da 'segurança'; $0,9 \%$ vai para 'ver seus ídolos', e 0,9\% vai pela 'acessibilidade'.

O estádio do Central é conhecido como o Lacerdão, e diversos são os fatores que influenciam um apaixonado por esportes a comparecer ao estádio. No caso do torcedor fã, o maior fator é ver seu clube jogar, visto que o maior prazer de um torcedor parece ser o de acompanhar, de perto, seu clube em uma competição. É possível sugerir que a autoestima de um torcedor tende a aumentar quando seu clube vence as competições, e demandas emocionais parecem bem contempladas quando os torcedores estão no estádio, participando desses momentos, ainda que a vitória do time não seja algo imprescindível ao torcedor-fã, conforme sugerem alguns dos entrevistados, nos trechos a seguir: torcedores, que nas vitórias comemoramos juntos e nos momentos difíceis, sofremos juntos. Porém o mais importante é o amor que temos em comum, o amor ao nosso time, sempre na esperança de dias melhores e sabemos que nosso time é capaz (T5 - Sócio-torcedor do Central Sport Club).

$\mathrm{O}$ Central independente de vencer ou perder, é uma situação de bem- estar, amor, muita paixão (T6 - Sócio-torcedor do Central Sport Club).

Clube que me ganhou pelo emocional. A vontade e garra dos jogadores junto com a torcida, o amor pela vontade de ver o time crescer encheu meu coração de vontade também. Bastou assistir a um jogo no estádio que o central me ganhou, mesmo perdendo o jogo kkkkk (T7 - Sócio-torcedor do Central Sport Club).

No tocante à comunicação com os torcedores, a internet se mostra meio proveitosa para as organizações esportivas aumentarem sua popularidade por meio das redes sociais, impactando o modo como os torcedores e fãs se aproximam do esporte (MOKFIANSKI; ALVETTI, 2017). No caso do Central, em relação às mídias mais utilizadas pelos entrevistados para acompanhar notícias de esportes, 46\% responderam 'mídias sociais online', 28, 3\% 'internet', 20,4\% 'rádio', 3,5\% 'televisão' e apenas $1.8 \%$ ‘jornal' (Gráfico 2).

Lugar que nos faz sentir em casa, principalmente pelo acolhimento dos

Gráfico 2 - Mídia mais usada para acompanhar notícias esportivas
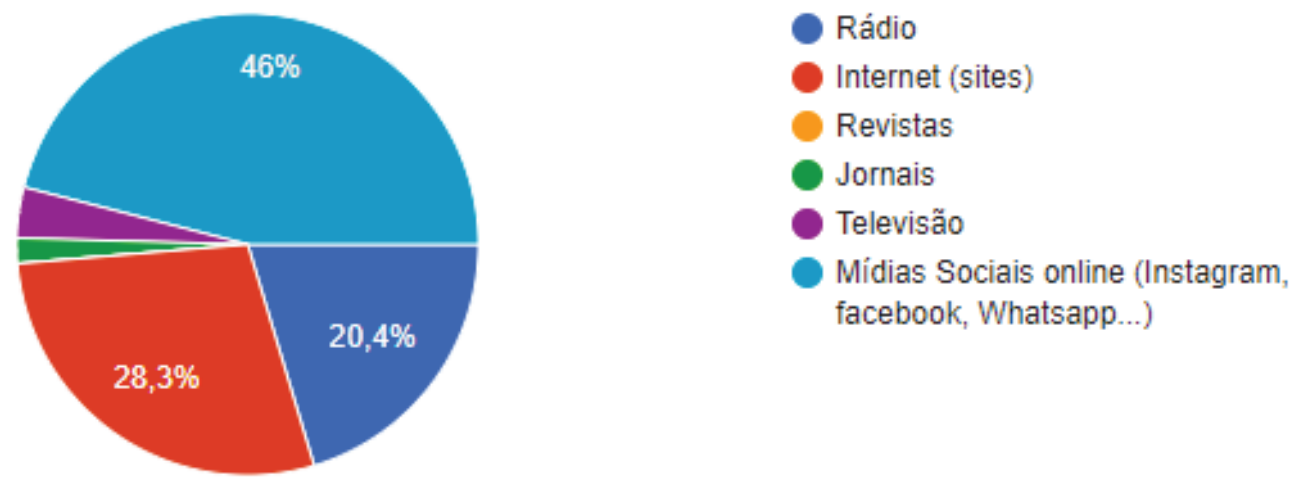

Fonte: dados da pesquisa de campo (2019). 
Os dados realçam a importância dos clubes do interior do Estado se atualizarem e investirem em suas redes sociais à medida que grande parte dos torcedores busca notícias rápidas, e as redes sociais oferecem essa vantagem. As redes sociais se apontam, cada vez mais, como meio para aproximar clube e torcedor, fortalecendo esse relacionamento para que a marca do clube cresça cada vez mais.

\subsection{RELACIONAMENTO DO SÓCIO- TORCEDOR COM A MARCA CENTRAL SPORT CLUB}

Esta seção enfatiza o relacionamento do torcedor com o Central Sport Club. Além de abordarmos a importância do Marketing Esportivo para os clubes de futebol, enfatizamos a importância do Marketing de Relacionamento e suas estratégias para captar clientes. Como discutimos, o futebol possui um grande diferencial em seu mix de marketing o $5^{\circ} \mathrm{P}$, a Paixão, o que envolve com muita força, física, mental e emocionalmente os torcedores.

Buscamos verificar o 'tempo de associação' entre os torcedores e o clube, visto que $53,5 \%$ são sócios de 1 a 5 anos, enquanto
21,9\% são sócios há mais de 10 anos. Ainda, $18,4 \%$ são sócios há menos de 1 ano, e $6,1 \%$ de 6 a 10 anos. É pertinente destacar que, conforme destacou a Diretoria do clube, a faixa para sócios até o ano de 2017 era de apenas uma, no valor de $\mathrm{R} \$ 100,00$. Com a mudança na gestão em 2018, foram criadas novas faixas, com intuito de atender mais públicos. Esse aspecto converge com estudo de Moreira e Lobato (2014), o qual sugere que o clube deve definir faixas de renda que representem seus clientes/ torcedores para que as estratégias de programas de sócios-torcedores sejam mais efetivas.

Quanto à definição do relacionamento dos torcedores com o Central Sport Club, $55,3 \%$ se consideram 'fanáticos', enquanto $31,6 \%$ se consideram 'muito participativos', $11,4 \%$ 'moderado', $0,9 \%$ eventual, e apenas $0,9 \%$ pouco participativo (gráfico 3 ). Esses dados estão muito próximos daqueles apontados na seção anterior, quando os entrevistados foram indagados quanto e como se definem como torcedor. É possível sugerirmos que tenha havido uma sobreposição na percepção dos entrevistados entre ser torcedor (de forma ampla, contemplando outras modalidades esportivas) e ser torcedor do Central.

Gráfico 3 - Relacionamento dos torcedores com o Central Sport Club

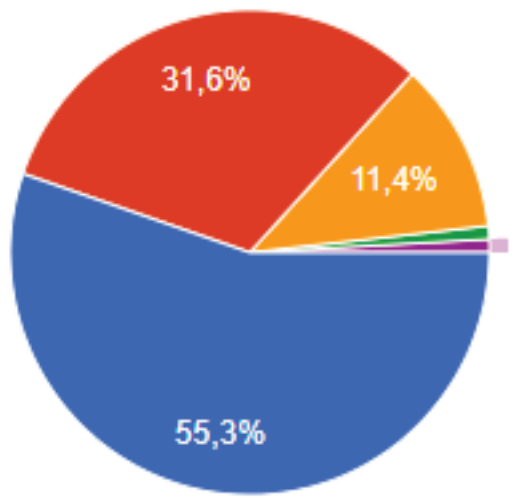

Fonte: dados da pesquisa de campo (2019).

Foi indagado que acerca da principal ideia que o torcedor gostaria que fosse associada ao Central Sport Club ou à equipe e transmitida aos sócios e torcedores. Os resultados apontam que $36 \%$ consideram que a 'força' deve ser a principal ideia, enquanto $24,6 \%$ a 'ação', 10,5\% 'liderança', 10,5\% 'Energia', $8,8 \%$ desafio, $3,5 \%$ disciplina e $6,1 \%$ outros.

A pergunta aberta do formulário solicitava ao entrevistado que definisse, em breves 
palavras, 'o que o Central Sport Club representa para você'. Dos 144 participantes, 99 responderam a essa pergunta. Foi conduzida uma análise temática (AT) para identificar e agrupar os temas ligados às respostas, visto que era possível que, em uma mesma resposta, houvesse mais de um tema. Os temas amplos ligados às principais visões da representação do clube na vida do torcedor foram identificados como (1) Paixão/ razão para viver (2) Amor/ eterno amor (3) Herança de gerações anteriores (4) Lazer e diversão (5) História e cultura e (6) Emoções.

Foi gerada (a partir do site wordart.com) nuvem de palavras que melhor ilustra essas ênfases da relação torcedor-time (figura 1). Conforme é possível observar, a partir do tamanho das palavras (o qual indica a maior frequência desses termos nos dados), os termos mais citados foram 'paixão' (30 ocorrências); 'amor' (29 ocorrências); Central (27 ocorrências); 'vida' (14 ocorrências) e 'clube' (14 ocorrências).

Figura 1 - Nuvem de palavras: 'defina o que o Central representa para você'

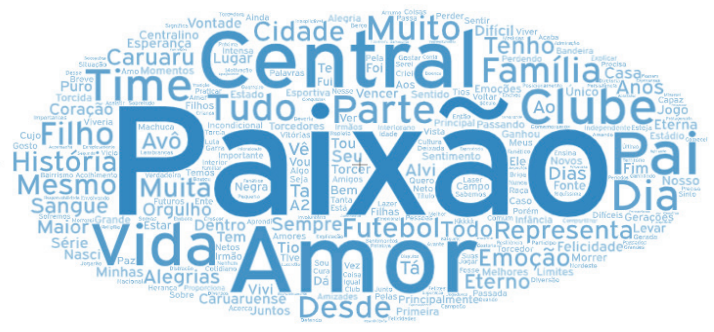

Fonte: dados da pesquisa de campo (2019).

Os sócios-torcedores do clube enfatizam a paixão pelo time, o amor eterno pelo clube; destacam a cultura ligada à cidade de Caruaru - PE, da herança que vem de gerações anteriores, e mostra que a paixão pelo futebol e os clubes do Brasil ultrapassa fronteiras, ideias bem ilustradas no trecho de um torcedor que não é natural de Caruaru, mas que se define como fanático pelo Central e consegue captar bem o imaginário em torno desse time do interior:

[O Central] representa uma paixão involuntária, que ensina (independente de posicionamento que esteja, ou seja, ou ganhando ou perdendo) muito sobre resiliência, persistência, esperança e, sobretudo, acerca da riquíssima cultura de Caruaru, sentimentos que são passados de pai pra filho e de filho pra neto. E esse sentimento também é sentido até mesmo por pessoas que não são de Caruaru (como no meu caso), mas, que, por tanta admiração a tudo que se passa dentro da torcida, acaba se envolvendo completamente (T8 Sócio-torcedor do Central Sport Club).

Assim, grande parte dos respondentes se relaciona como sendo 'fanático' pelo Central, o que é muito importante para o clube, já que o tamanho da torcida é o principal fator na determinação do potencial do clube, seja em receitas e incentivos aos atletas. A admiração pela torcida também é um ponto enfatizado pela maioria dos torcedores, dado que a torcida é o aspecto-chave dos clubes. Ora, os clubes de pequeno e médio porte, principalmente clubes do interior, têm diversos desafios para se manterem rentáveis. Os alvos dos grandes patrocínios e direitos de imagem para televisão tendem a ficar com os grandes clubes, por representarem maiores vitrines, em maiores cidades e maior quantidade de torcedores. Outro desafio são os calendários de jogos e as séries participantes: quanto menor a divisão, mais os clubes sofrem. À medida que os clubes se engajam para fortalecer, junto a seus torcedores, o sentimento de força e ação, os torcedores se sentem mais próximos do time, o que colabora com o crescimento e organização do clube. Essa ideia pode ser ilustrada na perspectiva de alguns respondentes:

Representa o orgulho caruaruense, a emoção do futebol no seu estado mais difícil que é o futebol interiorano, o Central tem tudo para ser time de série B (T9 - Sócio-torcedor do Central Sport Club).

Clube grande do interior do Nordeste que precisa voltar a ser protagonista (T10 - Sócio-torcedor do Central Sport Club). 
Consideramos uma avaliação acerca dos níveis de satisfação dos sócios com os seguintes aspectos do clube: plano de sócio e suas categorias; preço dos ingressos; a área do estádio destinada aos sócios (ex.: arquibancada e cadeiras); a comunicação do clube com o sócio-torcedor (ex.: informações sobre contratações, jogos, produtos, ingressos etc.); promoções, descontos e vantagens oferecidas pelo clube para sócios; segurança. Nenhum dos aspectos avaliados ficou abaixo da média, o que é muito importante para o clube o feedback desses torcedores.

Quanto ao 'plano de sócios e suas categorias', a média para esse item, em uma escala de 1 a 5, ficou em 3,93. O 'preço dos ingressos' ficou com a maior média, totalizando 4,21 (tabela 1). O departamento responsável pela venda de ingressos divide valores diferentes para cada área do estádio e lança promoções para datas comemorativas, como, no Dia das Mães, a promoção "Mãe de torcedor não paga", ação de marketing para atrair o público aos estádios a partir de um viés relacional ligado ao fortalecimento de vínculos afetivos entre torcedores.

Tabela 1 - Nível de satisfação dos sócios-torcedores

\begin{tabular}{l|l}
\hline \multicolumn{1}{c|}{ Aspecto avaliado } & \multicolumn{1}{c}{$\begin{array}{c}\text { Nível de } \\
\text { satisfação } \\
\text { (média) }\end{array}$} \\
\hline $\begin{array}{l}\text { Plano de sócios e suas cate- } \\
\text { gorias }\end{array}$ & 3,93 \\
\hline Preço de ingressos & 4,21 \\
\hline Segurança & 3,77 \\
\hline Área destinada aos sócios & 3,66 \\
\hline Comunicação com o torcedor & 3,60 \\
\hline $\begin{array}{l}\text { Vantagens, promoção e des- } \\
\text { contos para sócios }\end{array}$ & 3,42 \\
\hline
\end{tabular}

Fonte: dados da pesquisa de campo (2019).

O item 'segurança' nos estádios obteve média 3,77. A segurança nos estádios é um assunto polêmico, sendo que, muitas vezes, até a própria torcida como forma de protesto colabora com a violência, entre outros problemas com torcidas organizadas. É importante que os torcedores se sintam seguros nos estádios, para que, assim, possam levar sua família e continuar tendo a visão do futebol como entretenimento. É necessário estimular a ida aos estádios à medida que, em termos financeiros, os sócios torcedores representam uma fonte de receita menos volátil, não apenas pelas mensalidades pagas aos clubes, mas também pela maior predisposição em comparecer aos jogos e em comprar itens com a marca licenciada dos seus times (MONTEIRO; DIAS; CARVALHO, 2019).

Quanto à área destinada aos sócios, como arquibancada e cadeiras, a média de satisfação entre os entrevistados é de 3,66. Os torcedores obtêm lugares diferenciados nos estádios por se associarem ao clube. A 'comunicação' do clube com o torcedor obteve média 3,60, visto que de vital importância a ação do departamento de comunicação junto aos torcedores. Além das redes sociais e mídias para divulgação de notícias, o departamento de comunicação precisa estabelecer conexão com o torcedor para ouvir feedbacks, críticas e novas sugestões. Quanto às 'vantagens oferecidas para os sócios' como descontos e promoções em empresas parceiras, observou-se uma média de 3,42 de satisfação entre os sócios-torcedores do Central na pesquisa.

\section{CONSIDERAÇÕES FINAIS}

Buscou-se, neste estudo, identificar as estratégias de marketing esportivo usadas na gestão do relacionamento com o sócio-torcedor do Central Sport Club, time de Caruaru-PE, a partir da análise da percepção de seus clientes mais ativos (os torcedores). Este estudo de caso discorreu, ainda, acerca de aspectos da gestão dos clubes de futebol e estratégias de marketing implementadas no time Central Sport Club.

Verificou-se, desde já, que, na gestão do Central, o aumento para três das categorias disponíveis para a associação dos torcedores, oferecendo vantagens e valores diferentes, foi estratégia que alavancou, significativamente, o crescimento do rol de sócios-torcedores em menos de dois anos. A gestão do departamento social ampliou as chances para torcedores de 
diferentes perfis variados de renda escolherem em qual categoria podem-se encaixar.

Por meio do levantamento junto aos torcedores, identificou-se que os entrevistados também são, em sua maioria, consumidores, tanto do serviço, como do produto, isto é, o torcedor que frequenta os estádios também pratica esportes em horas de lazer, elevando a chance de consumirem produtos e acessórios ligados à marca Central Sport Club. Além disso, à medida que vão aos estádios para acompanharem as competições, para a maioria, o fator de maior motivação é o de ver o time jogar. Esse fator - ida aos estádios- está relacionado à segurança, preço dos ingressos, área destinadas aos sócios e à comunicação do clube com os torcedores, todos pontos interligados e bem avaliados pelos entrevistados.

A noção de forte representatividade do time Central Sport Club na vida dos torcedores participantes na pesquisa é respaldada pela literatura em marketing esportivo e de relacionamento, já que foram identificados como temas centrais na relação Central-torcedor a paixão, o amor pelo time, a influência das gerações anteriores, a conexão com o lazer e a diversão, a relação do time e dos torcedores com história e cultura locais, bem como as diversas emoções ligadas ao futebol.

É importante ressaltar que existem grandes lacunas ao se estudar os clubes do interior, uma vez que o olhar da mídia e os importantes patrocinadores ainda são muito voltados aos grandes clubes, os que possuem maior quantidade de torcedores e investidores. Os clubes de pequeno e médio porte carecem de um olhar diferente e específico, para que possam sobreviver em um ambiente hipercompetitivo e continuarem vivos na cultura e na tradição de seus torcedores. Espera-se que este estudo tenha contribuído para avançar em lacunas de conhecimento acerca do uso de estratégias de marketing esportivo e de relacionamento por clubes nesse perfil, trazendo, em especial, a perspectiva de sócios-torcedores do Central Sport Club de modo a corroborar um debate em torno de melhorias na gestão de clubes.

Como limitação do estudo, destaca-se a impossibilidade de realizar uma pesquisa junto a todos os sócios-torcedores, tendo sido selecionada uma amostra por conveniência para coleta dos dados. Além disso, este estudo de caso poderia ser aprofundado por meio do acesso à perspectiva dos demais gestores quanto à manutenção das estratégias implementadas e à criação de novas, profissionalização e qualidade da gestão dos departamentos que compõem o clube, visto que, para este estudo, foi considerada a perspectiva da Diretoria de Marketing.

Compreende-se que o futuro dos clubes de futebol no Brasil reside em uma gestão profissionalizada e na busca indispensável por saúde financeira para se investir na estrutura do clube no geral, fortalecendo, assim, o time dentro de campo que é o principal fator, e as diversas formas de aproximar o torcedor e envolvê-lo com a marca. Há desafios crescentes, sobretudo, quando consideramos os impactos da pandemia do novo Coronavírus. No Brasil, as medidas de isolamento social e de reestruturação de funcionamento dos jogos nas diversas competições futebolísticas geraram impactos significativos sobre os clubes.

Lavieri e Carneiro (2021) apontam que, nas temporadas sem público, devido à pandemia, os custos de operação, com segurança, arbitragem, ambulância, limpeza do estádio, entre outros não puderam ser cobertos com as bilheterias habituais e venda de produtos nos estádios. Ainda, estima-se que programas de sócio-torcedor perderam entre $50 \%$ e $65 \%$ de sua base de assinantes, comprometendo os clubes. Entendemos que esses impactos demandam novos esforços investigativos para que se possam dimensionar os reflexos sobre a condição financeira desses clubes, bem como a relação deles com seus sócios-torcedores, configurando importante sugestão para futuras pesquisas.

\section{REFERÊNCIAS}

AIDAR, A.; FAULLIN, E. Futebol e Desenvolvimento socioeconômico. Cadernos FGV Projetos, Rio de Janeiro, v. 8, n. 22, p. 48-60, 2013. 
AVANCINI, J. et al. Sport Club Internacional 100 anos, 100 mil sócios. ESPM Central de Cases, p. 2-14, 2010.

BECHARA, M. Marketing Esportivo. Resultados com ética e compromisso social. Rio de Janeiro: [s.n.], 2001.

BORGES, M. Sócio-torcedor, quantos tem o seu time? Veja levantamento exclusivo com números e compare com rivais. 2020. Disponível em: https://www.espn.com.br/futebol/ artigo/_id/6623667/socio-torcedor-quantos-tem-o-seu-time-veja-levantamento-exclusivo-com-numeros-e-compare-com-rivais. Acesso em: 1 abr. 2021.

BRAUN, V;; CLARKE, V. Using thematic analysis in psychology. Qualitative Research in Psychology, v. 3, n. 2, p. 77-101, 2006.

CBF. CBF registra receita e investimento recordes em 2019. 2020. Disponível em: https://www.cbf.com.br/a-cbf/informes/index/ cbf-registra-receita-e-investimento-recordes-em-2019. Acesso em: 1 abr. 2021.

COSTA, E. S.; MOTA, I. C. Marketing de relacionamento como estratégia de marketing esportivo, no programa de sócio torcedor do Sport Club Corinthians Paulista. Revista FATEC Sebrae em debate, v. 3, n. 5, p. 95-113, 2016.

CROCCO, L. et al. Marketing de Mídia Social: uma hora por dia. Rio de Janeiro: Alta Books, 2009.

DUALIB, C. Marketing Esportivo no Brasil. In: STODAR, D. K. Como Desenvolver Planos de Marketing Esportivo com Sucesso. Tradução Carell, Fabiana. São Paulo: Ideia e Ação, 2005.

GIL, C. Como elaborar projetos de pesquisa. 6. ed. São Paulo: Atlas, 2017.
LAVIERI, D.; CARNEIRO, G. O buraco da pandemia. 2021. Disponível em https://www. uol.com.br/esporte/reportagens-especiais/bilheteria-socio-torcedor-tv-brasileirao-sem-publico-da-prejuizo-a-times/\#page1. Acesso em: 1 abr. 2021.

LEÃO, A. L. M. de; PAIVA JÚNIOR., F. G. de.; MELLO, S. C. B. de. (org.). Abordagens Qualitativas na Pesquisa em Administração. Recife: Ed. UFPE, 2016.

MARTINS, D. J. Q. Planejamento de eventos esportivos e recreativos. Curitiba: Intersaberes, 2018.

MELO NETO, F. P. de. Marketing Esportivo. Rio de Janeiro. BestSeller: 2013.

MOKFIANSKI, K.; ALVETTI, C. O uso das redes sociais pelos clubes de futebol: o Facebook do Coritiba Foot Ball Club. In: CONGRESSO BRASILEIRO DE CIÊNCIAS DA COMUNICAÇÃO, 40., 2017, Curitiba. Anais [...]. Curitiba: Intercom, 2017.

MONTEIRO, P. R. R., DIAS, P. S.; CARVALHO, L. C. Amor à marca no marketing esportivo: proposição de um modelo relacional dos vínculos emocionais e afetivos nos programas sócio torcedor. Revista Brasileira de Marketing, v. 18, n. 2, p. 55-79, 2019. Disponível em: https://doi.org/10.5585/remark.v18i2.3752. Acesso em: 28 mar. 2021.

MOREIRA, R.; LOBATO, P. Os Programas de sócio torcedores como marketing de relacionamento dos clubes com sua torcida dentro do futebol: o caso Vasco Da Gama (RJ). 2014. Disponível em: https://universidadedofutebol.com.br/wp-content/uploads/pdf/ ARTIGO \%20PROGRAMA\%20DE\%20S\%C3\%93CIOS $\% 20-\% 20$ VASCO $\% 20$ DA $\% 20$ GAMA.pdf. Acesso em: 2 abr. 2019.

NOVELI, M.; COSTA, C. C. M. O uso de mídias sociais pelo Sport Club Corinthians Paulis- 
ta. ReFAE - Revista da Faculdade de Administração e Economia, v. 9, n. 1, 2018.

PACHECO, E. L. Z. Marketing de Relacionamento: um estudo da aplicação ao mercado de eletroeletrônicos. 2001. Dissertação (Mestrado) - Fundação Getúlio Vargas, São Paulo, SP, 2001.

PITTS, Brenda G.; STOTLAR, David K. Fundamentos de marketing esportivo. São Paulo: Phorte, 2002.

\section{RAFIH, Y. S. E. O Patrocínio Nas Camisas}

De Futebol No Brasil: A revolução nos cofres dos clubes brasileiros. 2015. Disponível em: https://docplayer.com.br/47119629-O-patrocinio-nas-camisas-de-futebol-no-brasil.html. Acesso em: 3 abr. 2019.

RICHARDSON, R. Pesquisa Social: métodos e técnicas. 3. ed. São Paulo: Atlas, 1999.

ROCCO JUNIOR, A. J. et al. Marketing esportivo. Curitiba: Intersaberes, 2021.

SANTOS, T.; PAROLINI, P. Marketing esportivo. Curitiba: Contentus, 2020.

SILVA, O. Futebol, um negócio que move paixões. Futebol e Desenvolvimento Sócio-econômico. Cadernos FGV Projetos, Rio de Janeiro, v. 5, n. 13, p. 24-28, 2010.

SILVA, F. G.; ZAMBON, M. S. Gestão de Relacionamento com o cliente: novas regras da economia e o e-relacionamento. São Paulo: [s.n.], 2008.

SLOAN, L. R. The motives of sports fans. In: GOLDSTEIN, J. H. Ports, Games and Play: Social and psychological viewpoints. Hillsdale: Lawrence Erlbaum Associates, 1989.

SPORTS VALUE. Ranking dinâmico das receitas dos clubes brasileiros. 2020. Disponível em: https://www.sportsvalue.com.br/ ranking-dinamico-das-receitas-dos-clubes-brasileiros/. Acesso em: 1 abr. 2021.

WANN, D. L.; BRANSCOMBE, N. R. Sports fans: measuring degree of identification with the team. International Journal of Sport Psychology, v. 24, p. 1-17, 1993.

YANAZE, M. H. Gestão de marketing e comunicação: avanços e aplicações. 2. ed. São Paulo: Saraiva, 2011.

YIN, R. K. Estudo de caso: planejamento e métodos. 2. ed. Porto Alegre: Bookman, 2001. 